\title{
Kernos
}

Revue internationale et pluridisciplinaire de religion grecque antique

$13 \mid 2000$

Varia

\section{Alain MOREAU, Mythes grecs. 1. Origines}

\section{Isabelle Tassignon}

\section{(2) OpenEdition}

\section{Journals}

Édition électronique

URL : http://journals.openedition.org/kernos/1329

DOI : 10.4000/kernos.1329

ISSN : 2034-7871

Éditeur

Centre international d'étude de la religion grecque antique

Édition imprimée

Date de publication : 1 janvier 2000

ISSN : 0776-3824

\section{Référence électronique}

Isabelle Tassignon, «Alain moreAu, Mythes grecs. 1. Origines », Kernos [En ligne], 13 | 2000, mis en ligne

le 21 avril 2011, consulté le 21 septembre 2020. URL : http://journals.openedition.org/kernos/1329;

DOI : https://doi.org/10.4000/kernos.1329 
Alain Moreau, Mythes grecs. I. Origines, Montpellier, Université Paul-Valéry, Séminaire d'Étude des mentalités antiques, Publ. de la recherche, 1999. 1 vol. $15 \times 21 \mathrm{~cm}, 264$ p. ISBN : 2-84269-239-X.

Couronnement de trente années de recherches en mythologie grecque, l'ouvrage d'Alain Moreau se présente comme un recueil d'articles parus dans diverses revues et actes de colloques. Consacré aux mythes des origines, ce livre sera bientôt suivi de cinq autres, dont l'un portera sur l'initiation. La matière envisagée se structure autour de quatre thèmes évoquant ce que les Grecs considéraient comme étant intrinsèquement lié à leurs origines. Dans la première partie de l'ouvrage, l'A. se livre à une réflexion sur les origines de personnalités hérö̈ques; l'étymologie se révèle être un guide précieux pour l'étude de la naissance des protagonistes et du déroulement d'un mythe. L'étude des noms de héros et d'héroïnes tels Adraste, Andromaque, Déjanire, Polynice et Électre montre que ces noms renvoient à des traits de caractères véhiculés par les versions les plus anciennes des mythes. Les origines du monde telles qu'elles étaient perçues par l'imaginaire grec font l'objet de la seconde partie de l'ouvrage où sont abordés les mythes mettant en scène la race de Méduse et les divers mythes relatifs au thème du déluge. Procédant par comparatisme contrastif, l'A. met en lumière les causes originelles données par les mythes au Déluge (dans la version biblique, dans la version babylonienne d'Atrahasis et dans divers mythes grecs), puis s'interroge sur la signification de la notion de navigation. Le motif de l'esquif livré aux flots est une constante caractéristique de ce type de mythes. Dépassant alors le strict cadre de la navigation accomplie lors d'un déluge 'mais limitant l'enquête au monde grec, l'A. tente d'établir une typologie des embarcations de fortune utilisées par ces héros-navigateurs. L'embarquement aurait alors valeur de rite de passage; ceci se confirme d'autant mieux que les navigateurs sont des jeunes hommes, souvent éloignés du pouvoir par leur propre famille, destinés à devenir des héros. Au cas de Persée, de Dardanos, de Télèphe, ... signalés par l'A., on peut ajouter celui de Ténès, récemment étudié par Maria Rocchi (Monete di Tenedos: la doppia ascia di Tennes e dei granchi dell'isola, in N.F. Parise (éd.), Bernhard Laum. Origine della moneta e teoria del sacrificio. Atti dell'incontro di studio, Roma, 1995, Rome, 1997, p. 93-110).

Sans végétation, pas de vie sur Terre; aux origines du monde se rattachent aussi les mythes relatifs aux divinités de la végétation. C'est à ces mythes qu'est consacrée la troisième partie de l'ouvrage dans laquelle l'A. a réuni un dossier documentaire où un discobole (divin ou héroïque) atteint d'un funeste lancer de disque un héros. Le cas le plus représentatif est celui de Hyakinthos, passé de vie à trépas sous la violence d'un disque lancé par Apollon, mais dévié de sa trajectoire par Borée. Différents éléments du mythe montrent que Hyakinthos était vraisemblablement un ancien dieu de la végétation préhellénique, partiellement supplanté par Apollon. S'appuyant sur un riche matériel comparatif, l'A. développe l'idée que le disque est intimement lié, tant par son iconographie que par son symbolisme, aux dieux solaires. Enfin, dans la quatrième partie intitulée Loin dans l'espace, l'A. passe en revue l'imagerie littéraire véhiculée par les Grecs à propos des terres de confins. Ces terres ne sont d'ailleurs pas toujours appré hendées comme des exemples d'une barbarie primitive. Lorsqu'il s'agit de décrire les pays odorants liés à Aphrodite, les auteurs reconnaissaient une supériorité à Chypre, à l'Arabie Heureuse, merveilleux confins regorgeant de richesses olfactives. Chez Eschyle et Pindare, les terres lointaines sont présentées comme des lieux enchanteurs, exemples contemporains mais hélas, trop distants, de justice et de félicité. C'est toute la différence entre un Eschyle et un Hésiode qui rejette l'âge d'or dans le passé, aux origines des temps. Le thème de la 
barbarie originelle, et plus particulièrement du cannibalisme, est aussi abordé quand l'A. montre que si celui-ci est généralement attribué par les Grecs à l'Autre, on le trouve aussi en Grèce : en Arcadie - pays qui passait pour attardé et à Mycènes, berceau même de la civilisation grecque.

Ouvrage exemplaire sur le plan de la méthode puisqu'il se trouve au point de convergence du comparatisme, de l'anthropologie et de la philologie, Mythes grecs convie à une réflexion sur la notion d'altérité dans l'antiquité et dans le monde moderne. Livre riche d'observations subtiles, il se révèle une mine d'informations érudites. Un index explicatif des noms de personnages permet utilement de faire le point dans un ouvrage qui brasse une matière dense et variée, ouvrant sur de très vastes horizons, tandis qu'une bibliographie mise à jour le complète utilement.

Isabelle Tassignon (Université de Liège)

Maria Lucia SANCASSANo, Il serpente e le sue immagini. Il motivo del serpente nella poesia greca dall Tliade all'Orestea, Como, Edizioni New Press, 1997. 1 vol. $17 \times 24 \mathrm{~cm}, 205$ p. (Biblioteca di Athenaeum, 36)

Ce texte d'une dissertation doctorale soutenue à l'Université de Marbourg en 1994 est le résultat d'une recherche philologique impeccablement menée, d'Homère à Eschyle en passant par la Théogonie d'Hésiode et les Lyriques. C'est donc toute la littérature grecque archaïque qui se trouve mise en coupes selon le thème récurrent, analogique, métaphorique et symbolique du serpent.

Motif d'épisème apotropaïque sur les écus de certains combattants, le serpent joue également dans l'Iliade un rôle oraculaire non négligeable en conjonction avec l'aigle notamment (XII, 200 et $s q$.). On le trouve aussi, dès le récit du départ en Aulide et jusqu'aux prodromes de la chute de Troie, lié à des images d'anticipation, le plus souvent funestes. Toutefois, en certains contextes, la connotation d'une valorisation positive qui s'y associe n'échappe pas à la sagacité de l'analyste.

Pour Hésiode, les choses se présentent différemment : l'animal y est vu sous des formes diverses comme un monstre répulsif, issu des ténèbres et finalement rejeté aux confins du monde «rationnel ». L'influence du Proche-Orient est dûment mentionnée par l'A. en ce qui concerne cet aspect négatif et proprement tératologique. De Pindare à Théognis, la moıkı $\lambda l \alpha$ des valeurs symboliques du reptile semble exprimer au mieux sa nature bifide et ambivalente. Il peut être nourricier autant que redoutable (Pind, Ol., VI, 39-47; Théogn., 599-602). Quant à l'Orestie qui semble être le véritable point de départ de toute cette enquête, elle

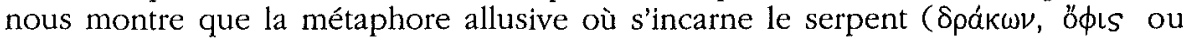
$\ddot{E} \chi\llcorner\delta \vee a)$ court tout au long du récit, dans les Choépbores surtout, ainsi qu'un fil de trame des plus évocateurs. De l'allusion initiale aux « petits de l'aigle » victimes du serpent jusqu'à l'apparition des Érinyes à un Oreste devenu lui-même

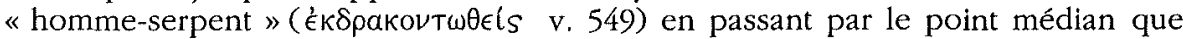
représente le fameux cauchemar de Clytemnestre (vv. 526-534), on assiste au rôle sémantiquement inducteur de cette métaphore eschyléenne, héritée d'un lointain passé et habilement réactivée en fonction des besoins de la progression dramatique. Rien d'essentiel n'échappe à l'œil de l'A., rien d'accidentel non plus, puis qu'elle a pris soin de débusquer son thème dans les ceuvres d'Eschyle précédant l'Orestie. Tout cet ensemble est bien convaincant. La perspective historico-religieuse y est toujours présente ainsi que toujours ouverte la perspective symbolique que requiert un pareil sujet. On peut seulement regretter qu'elle n'ait pas 